\title{
Identification and discrimination of consonant-vowel syllables by younger and older adults
}

\author{
LOIS L. ELLIOTT, LU ANN BUSSE, and LAURA L. BAILET \\ Northwestern University, Evanston, Illinois
}

\begin{abstract}
The purpose of this experiment was to determine whether age-related differences would be observed among adults in the identification and discrimination of synthesized 5 -formant consonantvowel syllables in which the voiced-stop consonants varied in the place-of-articulation feature. Listeners were aged 18-23 and 60-75 years, and all had pure-tone averages $\leq 25$. $\mathrm{dB} H \mathrm{HL}$. The older listeners exhibited poorer syllable identification thresholds, more shallow identification functions, larger just noticeable differences, and poorer free response performance than younger listeners. Among the older listeners, those with high-frequency sensitivity $\geq 30 \mathrm{~dB} \mathrm{HL}$ at $4 \mathrm{kHz}$ had poorer free responses to syllables than those with better $4-\mathrm{kHz}$ thresholds. In other respects, high frequency sensitivity did not discriminate among older listeners. Explanations considered as accounting for the observed age-related differences included frequency discrimination, since sensitivity, alone, did not account for the results.
\end{abstract}

To study developmental changes in perception, one technique involves the use of a continuum of synthesized consonant vowel (CV) syllables in which the voiced stop consonants differ along the dimension of place of articulation. When Elliott, Longinotti, Meyer, Raz, and Zucker (1981) measured the smallest between-syllable difference that could be discriminated (here termed, "just noticeable differences," or JNDs), they found that normalhearing 6-year-old children had larger JNDs than normal 10-year-olds or normal adults. In other work, which used only the three exemplars [ba], [da], and [ga], Elliott, Longinotti, Clifton, and Meyer (1981) found that 6-year-old children required higher intensities to identify these syllables and also exhibited more shallow slopes for their performance-intensity functions than did 10-year-olds. The finding that young children had higher syllableidentification thresholds agreed generally with results showing that young children require higher levels than adults to identify very familiar words (Elliott et al., 1979, Elliott \& Katz, 1980). The mechanism that underlies the shallow slopes of performance-intensity functions for certain population groups is unknown.

Another study (Elliott \& Busse, 1985a) revealed that $60 \%$ of severely learning-disabled young adults showed abnormal JNDs. Indeed, their JNDs for the [ba, da, ga] continuum resembled the performance of normal 6-yearolds. Performance of the learning-disabled young adults on the identification tasks showed considerable between-

Portions of this research were supported, in part, by NSF Grant PFR 79-06496.

The authors' mailing address is: Human Communication Sciences, Department of Communicative Disorders, Northwestern University, Frances Searle Building, 2299 Sheridan Rd., Evanston, IL 60201. subject variability. Some exhibited performance-intensity slopes that were steeper than their normal age-mates, but some demonstrated very shallow slopes. Only one of the learning-disabled adults had auditory sensitivity that was poorer than that of the normal controls, but this subject performed as well as normal age-mates on the JND and identification tasks. Thus, poor pure-tone sensitivity was not the basis for the aberrant results that were observed in the learning-disabled sample.

The experimental protocols used in testing these different samples of children and learning-disabled adults included forced-choice procedures with trial-by-trial feedback. Analyses of subjects' individual response patterns demonstrated that they did not develop response biases that might have been responsible for the observed larger JNDs, more shallow slopes, etc. Therefore, the most parsimonious explanation for these results was that auditory perception of children and many learning-disabled young adults differs from that of normal college-aged listeners.

The developmental changes for these tasks seen in children and special populations raised the question of whether older adults would perform in a manner similar to, or better/poorer than, 20-year-olds. Questions of particular interest concerned how the JNDs and slopes of performanceintensity functions of older adults compared with those of normal young adults and how performance on these experimental tasks related to pure tone sensitivity. There was secondary interest in determining whether performance of the older listeners on the experimental tasks would be related to performance on measures of psychological function. This point was considered because both the young normal children and the learning-disabled young adults of previous studies had differed from normal young adults in some aspects of cognitive ability, and because 
Table 1

Synthesis Parameter Values at Waveform Onset

\begin{tabular}{ccccrrr}
\hline $\begin{array}{c}\text { Stimulus } \\
\text { Number }\end{array}$ & \multicolumn{2}{c}{ Formant Frequencies (Hz) } & \multicolumn{3}{c}{ Relative Formant Amplitudes (dB) } \\
\cline { 2 - 6 } & F2 & F3 & A2 & A3 & A4 \\
\hline 1 & 1000 & 2000 & -36 & -66 & -36 \\
2 & 1083 & 2108 & -36 & -66 & -36 \\
3 & 1166 & 2216 & -36 & -66 & -36 \\
4 & 1250 & 2325 & -36 & -66 & -36 \\
5 & 1333 & 2433 & -36 & -66 & -36 \\
6 & 1416 & 2541 & -36 & -66 & -36 \\
7 & 1500 & 2650 & -36 & -66 & 0 \\
8 & 1550 & 2450 & -26 & -66 & -1 \\
9 & 1600 & 2350 & -16 & -66 & -2 \\
10 & 1650 & 2250 & -6 & -66 & -3 \\
11 & 1700 & 2150 & -4 & -66 & -5 \\
12 & 1750 & 2100 & -2 & -66 & -6 \\
13 & 1780 & 2050 & 0 & -66 & -9 \\
Steady-State Vowel & 1240 & 2650 & 0 & 0 & 0 \\
\hline
\end{tabular}

NOTE - Formant amplitude parameters changed at different times after waveform onset. For example, the $A 3$ parameter for stimulus 5 changed to $-6 \mathrm{~dB}$ at $15 \mathrm{msec}$ and $0 \mathrm{~dB}$ at 25 msec into the waveform. The $A 3$ parameter for stimulus 6 changed to -3 and $0 \mathrm{~dB}$ at the same points of the waveform. F1 onset was $200 \mathrm{~Hz} ; \mathrm{Fl}$ steady state was $720 \mathrm{~Hz}$. F4 and F5 were constant at 3600 and $4500 \mathrm{~Hz}$, respectively.

the question had been raised as to whether a decline in cognitive ability might contribute to the difficulties experienced by older listeners in understanding speech (Hayes, 1981). Several recent studies have concluded that hearing problems of the elderly are peripheral and without a central component (e.g., Duquesnoy, 1983; Patterson, Nimmo-Smith, Weber, \& Milroy, 1982).

\section{METHOD}

\section{Subjects}

Two types of subjects participated. Twenty young-adult university students, aged 18-23 years, were tested in a single session as an elective activity for an introductory-level course. All had normal pure-tone sensitivity and normal tympanograms. The $14 \mathrm{fe}-$ males and 6 males comprised Group 1 of this study.

Forty subjects, aged 60-75 years, were recruited from the suburban areas north of Chicago and paid for their participation. Because the older subjects were given more test procedures than were the college-age subjects, they were tested in multiple sessions. The group of older subjects included 19 females and 21 males. Most males were either working in or retired from professional or technical positions. Most females had not had working careers but were active in community affairs. Nearly all had attended college. The older and younger subjects were approximately equal in socio-economic status.

All subjects had normal tympanograms in the test ear and puretone averages (PTA), at $.5,1$, and $2 \mathrm{kHz}$, that did not exceed $25 \mathrm{~dB}$ HL (re ANSI, 1970), which is considered to be within normal limits. None of the older subjects had ever sought clinical evaluation of their hearing or considered themselves as having significant hearing problems.

\section{Conventional Audiologic Tests}

Air conduction (AC) thresholds were obtained in both ears for the octave frequencies from $250 \mathrm{~Hz}$ through $8 \mathrm{kHz}$ using standard clinical procedures. If pure-tone sensitivity was relatively symmetrical, the test ear was chosen to correspond with the preferred hand. In cases of sensitivity differences exceeding $10 \mathrm{~dB} \mathrm{HL}$, the ear with better sensitivity was used.

Several procedures were administered to the older subjects in order to describe that sample. Standard bone conduction testing was con- ducted for the test ear to rule out any possibility of conductive hearing loss. Tone decay tests were given at $20 \mathrm{~dB}$ sensation level (SL) re pure tone thresholds at $500 \mathrm{~Hz}$ and $4 \mathrm{kHz}$ in both ears as a screening for clinically significant retrocochlear pathologies. (For several subjects with relatively severe hearing losses at $4 \mathrm{kHz}$, the second tone decay measure was obtained at $2 \mathrm{kHz}$.) Older subjects were also given the W-22 Test (recordings by Auditec of St. Louis) at $30 \mathrm{~dB}$ SL re speech reception threshold in quiet and at the same signal level but presented against a competing message background (W-22 $\mathrm{CM}$, signal-to-noise ratio $=0 \mathrm{~dB}$ ).

\section{Syllabic Stimuli}

CV stimuli were produced using an adaptation of Klatt's (1980) parallel/cascade synthesizer program (Indiana University version). A 5-formant, 13-item continuum that varied in the place of articulation feature ([ba, da, ga]) was synthesized. Each syllable had five formants with 5-msec initial bursts, and each differed from the others in onset spectra, formant-transition directions, and formant-transition durations (Table 1). Second- and third-formant frequencies (F2, F3) of stimuli 1, 7, and 13 were selected to be representative of a male talker with General American speech saying "ba," "da," and "ga." F2 and F3 for the remaining stimuli (Nos. 2-6 and Nos. 8-12) were spaced proportionately between F2 and $\mathrm{F} 3$ of these three best exemplar syllables. Sampling rate was $10,000 / \mathrm{sec}$, and a $5000-\mathrm{Hz}$ low-pass filter was employed. All stimuli were $300 \mathrm{msec}$ in duration and were equalized in RMS energy. Previous research had shown that normal 6- and 10-year-old children and normal young adults perceive stimuli 1,7 , and 13 of this continuum as "ba," "da," and "ga," respectively, essentially $100 \%$ of the time (Elliott, Longinotti, Clifton, \& Meyer, 1981).

\section{Experimental Auditory Tasks}

Free responses. Before subjects were introduced to other procedures that used the synthesized syllables, they were given five presentations, in random order, of syllables 1,7 , and 13 at $90 \mathrm{~dB}$ SPL ${ }^{1}$ and were instructed to "say exactly what you hear." The experimenter sat in the test booth with the listener and recorded each response.

Identification task. The syllable-identification task used a closedset, automated procedure. On each trial, a circle on a storage oscilloscope that was positioned in front of the subject marked the 300-msec observation interval for stimulus presentation. The subject pressed one of three response buttons to identify the stimulus as "ba," "da," or "ga." Positive feedback was given for each 
correct response by the circle's changing into a smiling face for $500 \mathrm{msec}$. For incorrect responses, the circle disappeared. The program that operated the test procedure was listener-paced. Onset of the next observation interval/syllable presentation occurred $1 \mathrm{sec}$ after the last response.

In this syllable-identification task, syllables 1,7 , and 13 were presented in random order and at different intensities. A preliminary series of trials enabled the experimenter to determine the set of stimulus levels at which the subject's identification of syllables varied from below $50 \%$ to nearly $100 \%$ correct. In subsequent test series, each of the three syllables was presented at five different intensities that differed in 5-dB steps; 10 trials per stimulus per level were given in a computer-controlled, intermixed random order. The slopes of the performance-intensity functions for identifying each of the three syllables were determined by fitting the data points (percent correct at each intensity level for two test series) with a logistic function. The identification thresholds for each syllable, defined as the $50 \%$ correct point, were also determined from the fitted logistic functions.

The automated test program for the syllable-identification task printed out a confusion matrix immediately after the last response of a test run. Any response bias (e.g., toward pushing the "ba" button every time the $\mathrm{CV}$ could not easily be identified) would have been immediately apparent. However, this did not occur. Previous work had shown that adults as well as children did not develop a response bias for this procedure, presumably because of the feedback routine (Elliott \& Busse, 1985b).

Just noticeable differences (JNDs). The smallest $\mathrm{CV}$ differences that could be discriminated were determined in relation to stimulus 7 and were measured separately in the direction of stimulus 1 ("ba") and in the direction of stimulus 13 ("ga"). All 13 CVs were used in this procedure. Stimuli were presented at $90 \mathrm{~dB}$ SPL, and a transformed up-down adaptive procedure that measured the $71 \%$ correct point (Levitt, 1971) was employed. Two stimuli were sequentially presented on every trial, and the listener's task was to judge them as "same"' or "different" by pushing one of two response buttons. A circle appeared on the storage display during the presentation of a stimulus pair. The two syllables of a discrimination trial were separated by $500 \mathrm{msec}$, and listeners had unlimited time in which to respond. Trial-by-trial feedback was accomplished by the circle's changing into a smiling face after every correct judgment. The new trial began $1 \mathrm{sec}$ after termination of the 500 -msec feedback (or 1,500 msec after an incorrect response). Although stimulus 7 occurred on every test trial, its position (first or second of the two stimuli) was varied randomly. In addition to the test trials, there were catch trials in which both stimuli were identical and the expected response was "same." Catch trials were employed to keep listeners from developing a response bias towards responding "different" on nearly every trial, which would lead to spuriously small JNDs. The catch trials, which consisted of two identical syllables, were inserted randomly by the computer that controlled the experiment; there were equal numbers of test and catch trials. Catchtrial stimuli were syllables $5,6,7,8$, or 9 . Responses to catch trials were not used in calculating the JND. Instead, listeners were expected to obtain at least $75 \%$ correct performance on catch trials. This level was selected as midway between chance performance, or $50 \%$ correct, and perfect performance, which was unreasonable to expect. All listeners met this criterion except the three described below.

Pairs of stimuli were presented on each trial until the listener's responses to the adaptive procedure showed eight reversals. The continuum numbers (1-13) of the comparison stimuli for the last six reversals were averaged; the difference between this average and 7 , the continuum number of the anchor syllable, provided each measure of the JND. Two measures of each JND were obtained and averaged for every listener.

\section{Psychological Tests}

Two non-linguistically-based tests, designed to evaluate central, nonauditory skills, were selected for their game-like characteris- tics and because measures of central functioning, with little auditory or linguistic influences, were desired. One measure was the Block Design subtest of the Wechsler Adult Intelligence ScaleRevised (Wechsler, 1981). This procedure requires subjects to replicate pictured geometric designs by manipulating colored wooden cubes. Nine designs are used and time limits for performance are fairly stringent. A number of investigators have concurred in demonstrating a rather precipitous decline in performance between the ages of 20 and about 75 years (see review by Salthouse, 1982).

The second psychological test was the Concept Formation subtest from the Woodcock-Johnson Psycho-Educational Battery (Woodcock \& Johnson, 1978). Stimuli for this procedure are a number of picture plates depicting colored geometric shapes. Subjects are required to isolate nonverbal attributes such as color, size, and/or shape that are critical for grouping certain geometric figures together, while excluding others.

Raw scores for the Block Design and the Concept Formation tasks were used in the data analyses. These two tasks were not given to members of Group 1 because they were full-time university students who had met rigorous admission criteria and who would be expected to perform well on this type of test procedure.

\section{Instrumentation}

The subjects were tested individually in a double-walled test suite. The discrimination and syllable-identification procedures were controlled by a PDP-11/10 computer with 16-bit D/A converter and associated hardware; TDH-49 headphones with Grason-Stadler 001 cushions were used.

\section{Procedures}

Standard procedures were followed for administering the clinical audiologic tests, which were given to all subjects first. Free responses to the three synthesized syllables were next obtained before subjects were told what they might expect to hear. The discrimination and syllable-identification tasks were then given in counterbalanced order across subjects. A practice run was provided for the discrimination task to ensure that the listener understood the procedure. Practice was also required for the syllable-identification procedures in order to set intensity levels for each individual listener (see previous discussion). Older listeners, unlike the students, reported for several test sessions and were given the two psychological tests on their final visit.

\section{Data Analyses}

Two approaches to analyzing the data were adopted. Differences between subject groups were examined using $t$ tests of mean differences and ANOVA procedures. Relations between auditory sensitivity and performance on the experimental tasks were examined using correlational procedures. Relevant correlation coefficients are mentioned in describing $\mathrm{t}$ - and $\mathrm{F}$-test results, although the primary discussion of correlational results is presented later.

\section{RESULTS}

Because the older subjects exhibited differences in puretone sensitivity at $4 \mathrm{kHz}$, they were divided into two groups for data analysis. One group, designated Group 2, had pure-tone sensitivity at $4 \mathrm{kHz}$ equal to or better than $25 \mathrm{~dB}$ HL. The others, Group 3, had pure-tone sensitivity at $4 \mathrm{kHz}$ of $30 \mathrm{~dB} \mathrm{HL}$ or poorer. Nineteen subjects were placed in Group 2; 21 were placed in Group 3.

Table 2, which summarizes basic information about the three groups of subjects, shows that Group 3 was slightly older and contained twice as many males as Group 2. There was major overlap between Groups 2 and 3 in performance on the W-22 in quiet, the Block Design, and the Concept Formation tests. Although ranges of W-22 
Table 2

Subject Characteristics

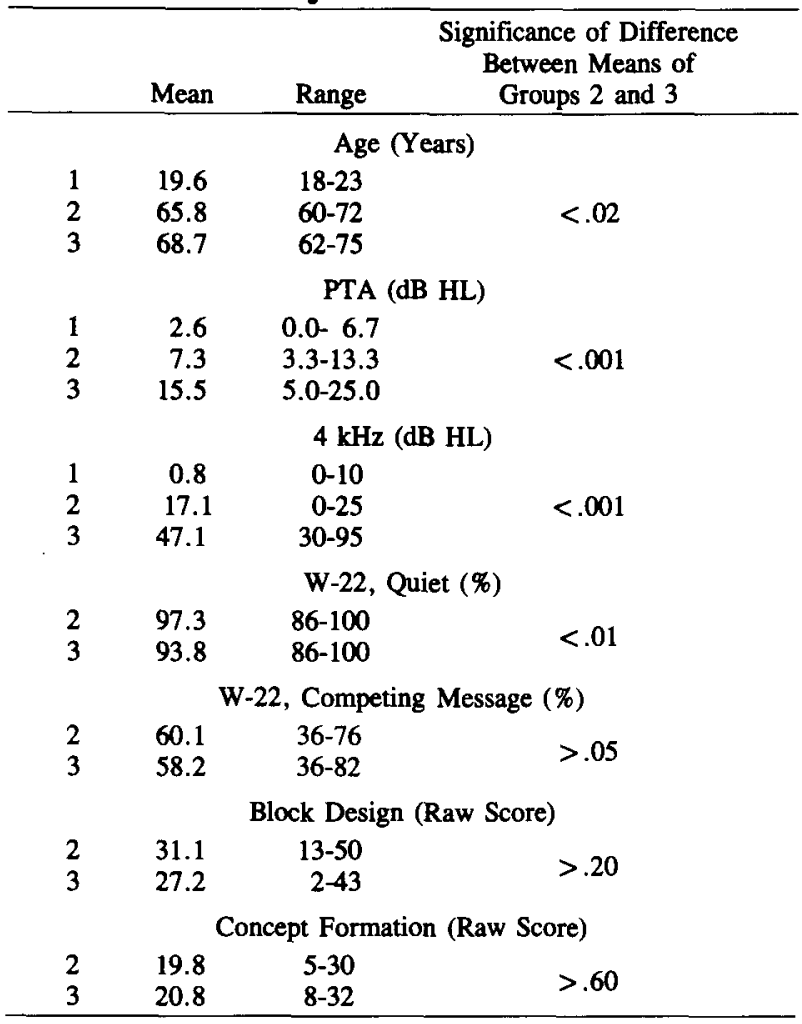

NOTE-Group 1, 6 males and 14 females; Group 2, 7 males and 12 females; Group 3, 14 males and 7 females.

scores in quiet were identical, the mean was significantly higher for Group 2 than for Group 3. Groups 2 and 3 did not differ significantly in performance on the Block Design and Concept Formation tasks.

\section{Free Responses}

The average number of correct free responses to the three syllables is shown in Table 3, along with the average total correct. Two measures of correct response are displayed: (1) the number of responses exactly correct (labeled 'correct"), and (2) the number of responses for which the initial consonant was correct. The second measure was made because many listeners gave a CVC response to some CV stimuli. Very often, when this happened, the listener responded by giving a meaningful word rather than a nonsense syllable. In these instances, the listener perceived more information about the CV stimulus than the listener who responded with an incorrect initial consonant. Older listeners gave more CVC responses than did college students, perhaps because the latter are more "test wise."

Table 3 indicates that, except for the count of initial consonants correct in response to stimulus 1 ([ba]), Group 3 gave numerically fewer average correct responses for every comparison than did Group 2 and performance of both groups of older listeners was numeri- cally poorer than that of the college-aged subjects of Group 1. When responses to all three stimuli were combined, Group 2 gave correct initial consonant responses to slightly more than two-thirds of the syllables, whereas Group 3 gave correct initial consonant responses to just slightly more than half of the stimuli $[\mathrm{t}(38)=3.2, \mathrm{p}<$ $.01]$. When interrelations between these outcomes and pure-tone sensitivity were examined (for the 40 subjects of Groups 2 and 3), the correlations between correct initial consonant and sensitivity were -.38 for PTA and -.55 for $4 \mathrm{kHz}$. The correlations between free responses and sensitivity were lower when based on totally correct free responses ( $r=-.21$ for PTA; and $r=-.32$ for $4 \mathrm{kHz}$ ). (Members of Group 1 were not included in these correlations because nearly all were at "ceiling" for the procedure and totally correct on every item; thus, these coefficients are not shown in Table 6).

\section{Identification Task}

More than one pilot run of the identification task was occasionally required (see previous discussion) to establish stimulus levels for every listener who produced identifications ranging from below $50 \%$ to at least $90 \%$ correct for each of the three syllables. The fit of the derived logistic functions to the data points was tested by chisquare procedures. The only instances of significant chisquare differences occurred when a listener's performance-intensity function reached a plateau (e.g., $90 \%$ correct identification at both 50 and $55 \mathrm{~dB}$ SPL). In these instances, the extreme data point (e.g., the point at $55 \mathrm{~dB}$ SPL) was dropped in recalculating the function and the $50 \%$ threshold.

Identification thresholds for the three syllables and for the three subject groups are shown in Figure 1. Differ-

Table 3

Mean Free Responses to Syllables 1, 7, and 13 by Members of the Three Subject Groups for Two Scoring Methods

\begin{tabular}{|c|c|c|c|c|}
\hline \multirow[b]{2}{*}{ Group } & \multicolumn{2}{|c|}{ Correct } & \multicolumn{2}{|c|}{$\begin{array}{l}\text { Initial Consonant } \\
\text { Correct } \\
\end{array}$} \\
\hline & Mean & SD & Mean & SD \\
\hline \multicolumn{5}{|c|}{ Syllable 1 ([ba])* } \\
\hline $\begin{array}{l}1 \\
2 \\
3\end{array}$ & $\begin{array}{l}4.5 \\
2.4 \\
1.6\end{array}$ & $\begin{array}{l}1.2 \\
2.2 \\
2.0\end{array}$ & $\begin{array}{l}4.7 \\
3.6 \\
3.6\end{array}$ & $\begin{array}{l}1.1 \\
1.8 \\
1.7\end{array}$ \\
\hline \multicolumn{5}{|c|}{ Syllable 2 ([da])* } \\
\hline $\begin{array}{l}1 \\
2 \\
3\end{array}$ & $\begin{array}{l}4.6 \\
2.6 \\
1.4\end{array}$ & $\begin{array}{l}1.2 \\
2.1 \\
2.1\end{array}$ & $\begin{array}{l}4.9 \\
3.8 \\
2.1\end{array}$ & $\begin{array}{l}0.4 \\
1.6 \\
2.1\end{array}$ \\
\hline \multicolumn{5}{|c|}{ Syllable 3 ([ga])* } \\
\hline $\begin{array}{l}1 \\
2 \\
3\end{array}$ & $\begin{array}{l}4.7 \\
2.7 \\
1.4\end{array}$ & $\begin{array}{l}0.8 \\
2.1 \\
1.7\end{array}$ & $\begin{array}{l}4.8 \\
4.1 \\
2.1\end{array}$ & $\begin{array}{l}0.8 \\
1.3 \\
2.1\end{array}$ \\
\hline \multicolumn{5}{|c|}{ All Syllables** } \\
\hline $\begin{array}{l}1 \\
2 \\
3\end{array}$ & $\begin{array}{r}13.8 \\
7.7 \\
4.4 \\
\end{array}$ & $\begin{array}{l}2.1 \\
5.5 \\
4.6\end{array}$ & $\begin{array}{r}14.3 \\
11.4 \\
7.8\end{array}$ & $\begin{array}{l}1.4 \\
3.1 \\
4.0\end{array}$ \\
\hline
\end{tabular}

*Maximum possible score $=5 . \quad * *$ Maximum possible score $=15$. 


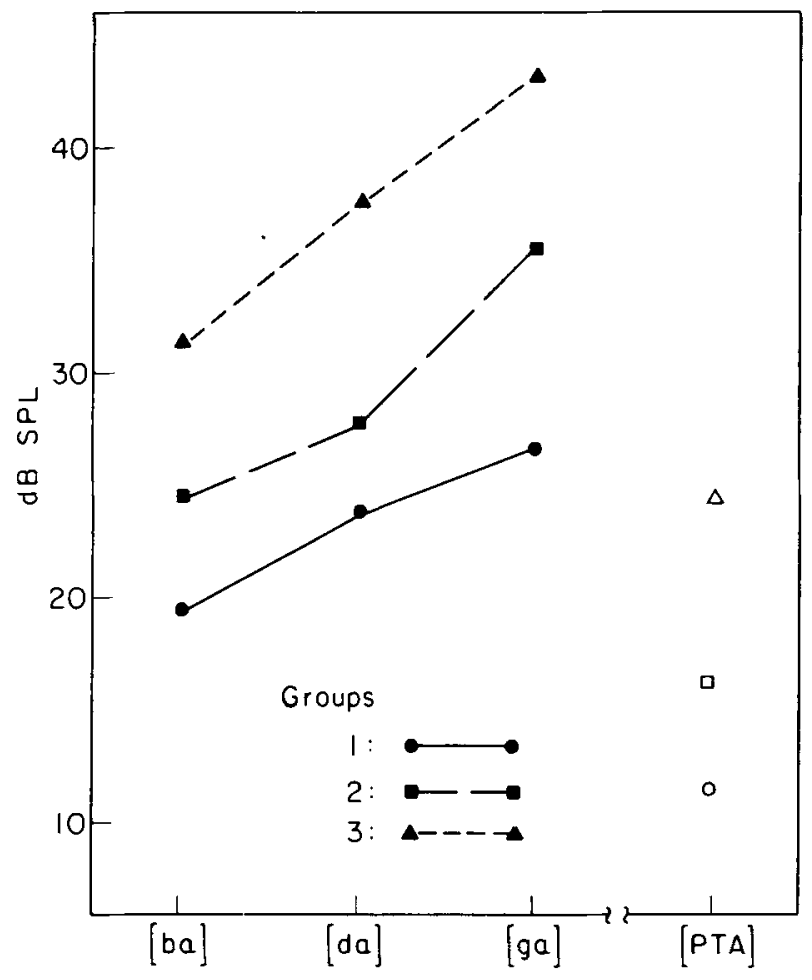

Figure 1. Identification thresholds for [ba], [da], and [ga], for the three subject groups, are shown by filled symbols. For comparison, pure-tone averages $(.5,1$, and $2 \mathrm{kHz})$ are shown by unfilled symbols.

ences among groups were statistically significant $[F(2,57)$ $=35.4, \mathrm{p}<.001]$, as might be expected on the basis of pure-tone sensitivity levels among the three groups. Statistically significant differences in identification thresholds occurred among syllables $[\mathrm{F}(2,114)=78.5$, $\mathrm{p}<.001]$, and the interaction between subject groups and syllables was also significant $[F(4,114)=2.5, \mathrm{p}<$ .05].

All subjects required higher intensities to identify syllable 13, [ga], lower intensities to identify stimulus 7 , [da], and lowest intensities to identify stimulus $1,[\mathrm{ba}]$-an outcome that was probably related to the acoustic characteristics of the stimuli. The syllables had identical total durations and were equalized in RMS energy. However, the relative intensities of the initial portions of the syllable were not equal (Table 4) as occurs in natural speech. Although listeners in all groups required higher levels to identify [ga] than to identify [ba] or [da], the interaction between groups and syllables occurred because the older subjects required a proportionally greater increase in level than did those of college age.

The slopes of the identification functions (Figure 2) revealed the same $\mathrm{V}$-shaped pattern that was reported previously (Elliott, Longinotti, Clifton, \& Meyer, 1981a), with slopes for [da] more shallow that slopes for [ga] or [ba] $[F(2,114)=7.0, p<.001]$. Figure 2 also illustrates the significant differences in slopes of identification functions that occurred between groups $[F(2,57)=7.6, p<.001]$. The college-age listeners of Group 1 had much steeper slopes of identification functions for all syllables than did the older listeners, and the average slopes for Group 3 were numerically smaller than those for Group 2, although this did not attain significance. The group $\times$ syllable interaction was not significant, probably because of within-group variability.

\section{JND Task}

Three older subjects, who performed well on the syllable-identification task, were unable to judge differences on the JND task consistently, even for stimuli differing as much as No. 1 and No. 7 or No. 7 and No. 13 . One subject in Group 3 could not distinguish stimuli 1 and 7; another could not discriminate 7 and 13; and one subject, in Group 2, could make neither discrimination. In these instances, 6 (the maximum difference between syllables) was used for the JND measure in data analyses. Except for these three older subjects, the range of catchtrial performance was $80 \%-92 \%$ correct for Group 1, 79\%-97\% correct for Group 2, and 78\%-97\% correct for Group 3.

Group means for JNDs measured in the direction of syllable $1([b a-d a] J N D)$ and in the direction of stimulus 13 ([da-ga] JND) are shown in Table 5. JNDs measured in the direction of [ga] were consistently larger (in syllable-step units) than those measured in the direction of $[\mathrm{ba}][\mathrm{F}(1,57)=51.7, \mathrm{p}<.001]$, as also occurred when younger listeners were tested (Elliott, Longinotti, Meyer, et al., 1981). Mean JNDs of Group 1 were smaller than those of Groups 2 and 3, which were very similar $[F(2,57)$ $=3.4, p<.05$ ]. If pure-tone sensitivity had exclusively determined magnitude of the JNDs, a larger difference might have been expected between the mean JNDs of Groups 2 and 3. Instead, some members of both Group 2 and Group 3 had relatively small JNDs, while other members of both groups had very large JNDs. The group $X$ JND interaction was not significant.

\section{Correlations}

Table 6 displays correlations among variables that were common to all three groups. Moderate correlations were obtained between PTA and sensitivity at $4 \mathrm{kHz}$ and among the syllable-identification thresholds. PTA had numerically higher correlations with identification thresholds than

Table 4

Relative RMS Levels (in dB) Measured from Waveform Onset to Various Points (in msec) Within the Stimulus

\begin{tabular}{crrr}
\hline (msec) & [ba] & [da] & [ga] \\
\cline { 2 - 4 } 8 & 4.3 & 0.0 & 7.5 \\
12 & 20.0 & 1.1 & 9.0 \\
19 & 23.2 & 17.3 & 9.4 \\
52 & 29.4 & 26.4 & 23.3 \\
79 & 29.9 & 27.7 & 24.5 \\
$300^{*}$ & 28.9 & 28.9 & 29.0 \\
\hline
\end{tabular}

Note-All levels relative to first 8 msec of [da]. *Full duration. 


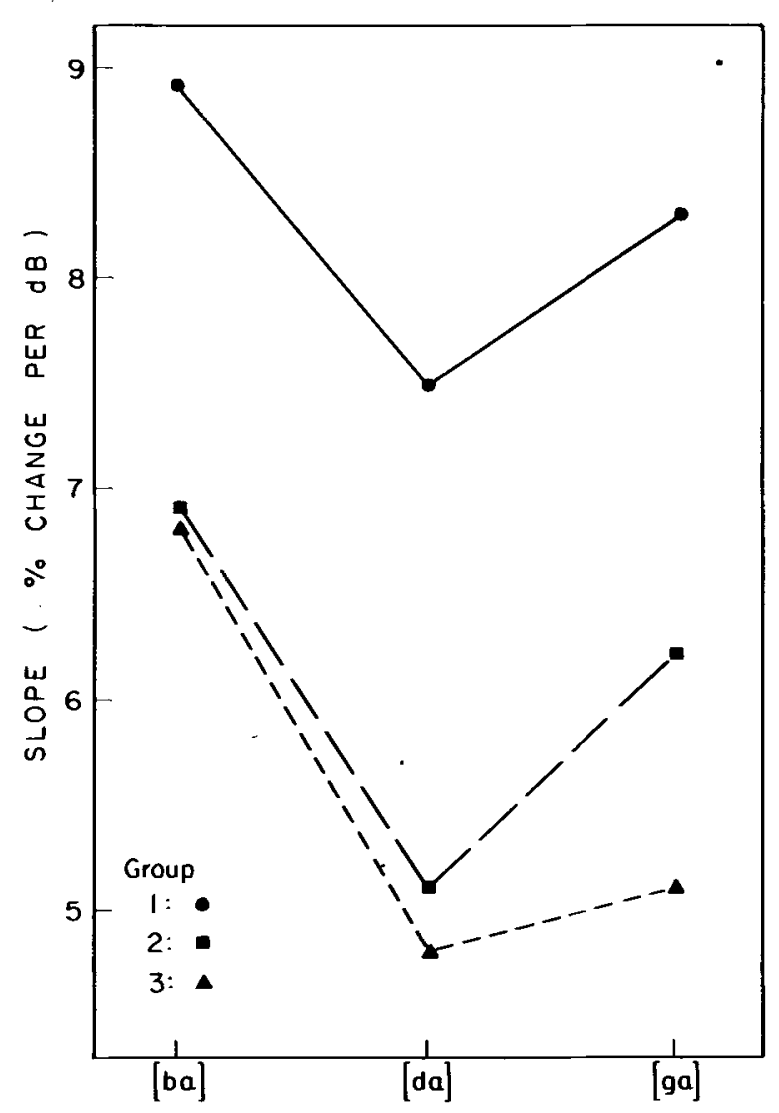

Figure 2. Slopes of the identification functions, in percent change per decibel, are shown for the three best exemplar syllables.

did sensitivity at $4 \mathrm{kHz}$, but both sets of correlations were significant at $\mathrm{p}<.01$.

Since members of Group 1 were considerably younger than members of Groups 2 and 3, biserial correlation coefficients were used to estimate the true correlations between age and the other variables. Age correlated well with PTA, $4 \mathrm{kHz}$, and the identification thresholds, as might be expected. Also, age correlated significantly and positively with the JNDs and significantly and negatively with the slopes of the identification functions.

Because age was also related to the measures of auditory sensitivity, two sets of partial correlations were derived-one eliminating the effects of PTA and the other eliminating the effects of 4-kHz sensitivity. These derived coefficients, which are shown in the second and third rows of Table 6, are based on a procedure that combined the biserial correlations pertaining to age with Pearson correlations. A correlation of age with identification thresholds, independent of pure-tone sensitivity (PTA and $4 \mathrm{kHz}$ ), was established only for [ga]. All six partial correlation coefficients relating age to the slopes of the identification functions achieved statistical significance at the .05 level; the coefficient between age and slope for the identification function for [ga], with PTA removed, was also statistically significant at the .01 level (one-tailed tests).
This result supported the outcomes of the ANOVA analysis, where differences in slopes of the performance identification functions occurred, even though the syllableidentification procedure included adjustment for individual differences in levels required for syllable identification.

The last column of Table 6 displays correlations of these variables with $\mathrm{W}-22_{\mathrm{CM}}$, for older listeners only. (Correlations were not run for the W-22 Test in quiet because of ceiling effects.) A negative correlation of -.32 occurred between sensitivity at $4 \mathrm{kHz}$ and $\mathrm{W}-22_{\mathrm{CM}}(\mathrm{p}<.025)$, but the other correlations with measures of auditory performance did not attain statistical significance. However, the correlation of W-22 $\mathrm{CM}$ with the Block Design test was $.33(\mathrm{p}<.025$, one-tailed test) and of the same magnitude as the correlation between $4 \mathrm{kHz}$ and $\mathrm{W}-22 \mathrm{~cm}$. (The apparent difference in the direction of these two correlations involving $\mathrm{W}-22 \mathrm{CM}$ occurred because a numerically large score for $4 \mathrm{kHz}$ denotes poor sensitivity, whereas a numerically large score on the Block Design subtest represents good performance.)

The correlation between the Block Design and Concept Formation psychological measures was .63 $(\mathrm{p}<.01)$. With the exception of a negative correlation between Block Design and the [da-ga] JND $(r=-.36, p<.025)$, no other correlations involving the two psychological measures were noteworthy.

\section{DISCUSSION}

Group 3 was generally poorer on the free response task than Group 1 or Group 2, as might be expected on the basis of Group 3's poorer pure-tone sensitivity. However, performance of Groups 2 and 3 did not differ for the JND task or identification slopes.

The finding that Groups 2 and 3 exhibited more shallow slopes for the identification functions than did the younger listeners of Group 1 indicated that the older listeners were not able to make as efficient use of the acoustic information, as intensity increased, as did the younger listeners. That is, compared with college-age listeners, members of Groups 2 and 3 required a higher level increase above the intensity at which they could identify syllables $50 \%$ of the time before they were able to make correct identifications nearly all of the time. One

Table 5

Mean Just Noticeable Differences Measured in the Directions of [ba] and [ga] for Three Subject Groups

\begin{tabular}{llll}
\hline & \multicolumn{3}{c}{ Groups } \\
\cline { 2 - 4 } & 1 & 2 & 3 \\
\hline \multirow{4}{*}{ Mean } & 1.5 & 2.1 & 2.0 \\
SD & 0.4 & 1.0 & 1.1 \\
& \multicolumn{2}{c}{ [ba-da] } \\
Mean & 2.5 & 2.9 & 3.1 \\
SD & 0.4 & 1.0 & 0.9 \\
\hline
\end{tabular}

Note-Units are intersyllable steps along the CV continuum. 
Table 6

Intercorrelation Matrix $(\mathrm{N}=\mathbf{6 0})$

\begin{tabular}{|c|c|c|c|c|c|c|c|c|c|c|c|}
\hline & 2 & 3 & 4 & 5 & 6 & 7 & 8 & 9 & 10 & 11 & 12 \\
\hline $\begin{array}{l}\text { 1. Age } \dagger \\
\text { Age. PTA }+\dagger \\
\text { Age. } 4 \text { kHz } \dagger \dagger\end{array}$ & $.77^{* *}$ & $.87 * *$ & $\begin{array}{l}.34^{* *} \\
.23^{*} \\
.11\end{array}$ & $\begin{array}{l}.36^{* *} \\
.15 \\
.21^{*}\end{array}$ & $\begin{array}{l}.69^{* *} \\
.14 \\
.23^{*}\end{array}$ & $\begin{array}{l}.69^{* *} \\
.14 \\
.10\end{array}$ & $\begin{array}{l}.76^{* *} \\
.26^{*} \\
.28^{*}\end{array}$ & $\begin{array}{l}-.37^{* *} \\
-.25^{*} \\
-.27^{*}\end{array}$ & $\begin{array}{l}-.47^{* *} \\
-.22^{*} \\
-.24^{*}\end{array}$ & $\begin{array}{l}-.52 * * \\
-.38 * * \\
-.22 *\end{array}$ & -.07 \\
\hline $\begin{array}{l}\text { 2. PTA } \\
\text { 3. } 4 \mathrm{kHz} \\
\text { 4. [ba-da] JND } \\
\text { 5. [da-ga] JND } \\
\text { 6. [ba] threshold } \\
\text { 7. [da] threshold } \\
\text { 8. [ga] threshold } \\
\text { 9. [ba] slope } \\
\text { 10. [da] slope } \\
\text { 11. [ga] slope } \\
\text { 12. W-22-Competing message }(\mathrm{N}=37)\end{array}$ & & $.70^{* *}$ & $\begin{array}{l}.14 \\
.27^{*}\end{array}$ & $\begin{array}{l}.29^{*} \\
.19 \\
.42^{* *}\end{array}$ & $\begin{array}{l}.78^{* *} \\
.58^{* *} \\
.02 \\
.25^{*}\end{array}$ & $\begin{array}{l}.78^{* *} \\
.71^{* *} \\
.23^{*} \\
.22^{*} \\
.71^{* *}\end{array}$ & $\begin{array}{l}.76^{* *} \\
.62^{* *} \\
.13 \\
.32^{* *} \\
.77^{* *} \\
.76^{* *}\end{array}$ & $\begin{array}{l}-.16 \\
-.11 \\
.06 \\
-.04 \\
-.08 \\
-.19 \\
-.13\end{array}$ & $\begin{array}{l}-.34^{* *} \\
-.28^{*} \\
-.07 \\
-.11 \\
-.35^{* *} \\
-.25^{*} \\
-.20 \\
.28^{*}\end{array}$ & $\begin{array}{l}-.19 \\
-.37^{* *} \\
-.06 \\
-.15 \\
-.09 \\
-.17 \\
-.16 \\
.41^{* *} \\
.54^{* *}\end{array}$ & $\begin{array}{l}.05 \\
-.32 * * * \\
-.22 \\
-.10 \\
-.05 \\
-.03 \\
.06 \\
-.17 \\
-.01 \\
.23\end{array}$ \\
\hline
\end{tabular}
test, $d f=58 . \quad * * * p<.025$, one-tailed test, $d f=35$.

may hypothesize that this difference occurred because older listeners had reduced frequency discrimination, as has been reported (Konig, 1957; Patterson et al., 1982). Frequency discrimination is known to improve as intensity increases (Wier, Jesteadt, \& Green, 1977), and it is possible that the rate of this improvement is faster in younger listeners. This basic psychophysical question merits investigation; no relevant data concerning changes in frequency discrimination as a function of intensity, as age varies, are known to the authors.

The CV parameters in Table 1 suggest that discrimination of the F2 and F3 onsets may have been more difficult for [ga] than for [ba-da] JND. That is, the difference between $F 2$ and $F 3$ onset values for [ba] and [da] was approximately $1000 \mathrm{~Hz}$, but the F2-F3 onset difference was only about $250 \mathrm{~Hz}$ for [ga]. This may explain why the [da-ga] JND was larger than the [ba-da] JND. Related to this point is the report from Turner and Nelson (1982) that listeners with high-frequency losses had larger than normal frequency difference limens (DLF) for unchanging tonal signals at all frequencies tested, including frequencies at which their sensitivity was normal. (It will be remembered that the pure-tone average for all listeners was within normal limits, but that Group 2 and particularly Group 3 had poorer 4-kHz thresholds than Group 1). Nevertheless, high-frequency losses and associated effects cannot completely explain the results, since mean JNDs of Groups 2 and 3 were quite similar (Table 5) despite the nonoverlapping distributions of sensitivity at $4 \mathrm{kHz}$ for these two groups. Furthermore, 6year-old children, with considerably better $4-\mathrm{kHz}$ sensitivity than the older adults of this study, have been shown to have larger JNDs (Elliott, Longinotti, Meyer, et al., 1981) and more shallow identification functions (Elliott, Longinotti, Clifton, \& Meyer, 1981) than college-aged adults. Thus, pure-tone sensitivity levels cannot be the variables controlling performance on the experimental tasks.

The lack of relation between experimental task performance and the psychological measures could be inter- preted as implying that central capabilities did not contribute to performance on these tasks. However, the significant correlation between Block Design and W-22 $\mathrm{CM}$ matched the magnitude of the correlation between the 4$\mathrm{kHz}$ threshold and the $\mathrm{W}-22_{\mathrm{CM}}$ score. Demonstrations of relations between language skills and speech perception in other age groups (e.g., Elliott, Clifton, \& Servi, 1983; Elliott et al., 1979) suggest that the issue of central contributions to speech understanding may deserve further investigation among older listeners, using other cognitive tests.

\section{CONCLUSIONS}

Experimental results may be summarized in seven main points. When the performance of 60-75-year-old listeners with PTAs $\leq 25 \mathrm{~dB}$ HL was compared with the performance of college-aged listeners, older listeners exhibited poorer free responses, poorer syllable-identification thresholds, more shallow slopes of performance-intensity functions for syllable identification, and larger JNDs. Of these first four points, only the second (poorer identification thresholds) may be completely explained by the difference in auditory sensitivity of older and younger listeners. In addition, when compared with their age-mates with better high-frequency sensitivity, older listeners with hearing levels $\geq 30 \mathrm{~dB} \mathrm{HL}$ at $4 \mathrm{kHz}$ had poorer free responses. Older listeners' performance on the experimental measures was not significantly related to their ability to identify words in noise. Finally, the Block Design subtest correlated significantly with the [da-ga] JND and with $\mathrm{W}-22_{\mathrm{CM}}$ among older listeners.

The clearest demonstration of age effects concerned the shallow slopes of the identification functions among the older listeners. The levels at which these functions were measured were adjusted for individual subjects, so auditory sensitivity differences across ages should not have been a directly contributing factor. Furthermore, the lack of greater differences on the experimental tasks for Groups 2 and 3 , in the presence of highly significant sensitivity 
differences, indicates that pure-tone thresholds were not the exclusive determinants of CV identification and JND performance. The explanation suggested as contributing to the age differences was poorer frequency discrimination among older listeners and, possibly, less improvement in frequency discrimination as stimulus level increased than occurred for younger listeners. This hypothesis merits further investigation.

\section{REFERENCES}

ANSI (1970). Specifications for audiometers (S3.6-1969). New York: American National Standards Institute.

DUQUESNOY, A. J. (1983). The intelligibility of sentences in quiet and in noise in aged listeners. Journal of the Acoustical Society of America, 74, 1136-1144.

Elliott, L. L., \& Busse, L. A. (1985a). Auditory processing by learning-disabled young adults. In D. Johnson \& J. Blalock (Eds.), Young adults with learning disabilities. New York: Grune and Stratton.

Elliott, L. L., \& Busse, L. A. (1985b). Syllable identification by children and adults for two task conditions. Journal of the Acoustical Society of America, 77, 1258-1260.

Elliot, L. L., Clifton, L. B., \& Servi, D. (1983). Word frequency effects for a closed-set word identification task. Audiology, 22, 229-240.

Elliott, L. L., Connors, S., Kille, E., Levin, S., Ball, K., \& KATZ, D. (1979). Children's understanding of monosyllabic words in quiet and in noise. Journal of the Acoustical Society of America, 66, 12-21.

ELLIOTT, L. L., \& KATZ, D. (1980). Development of a new children's test of speech discrimination. St. Louis: Auditec.

Elliott, L. L., Longinotti, C., Clifton, L., \& Meyer, D. (1981). Detection and identification thresholds for consonant-vowel syllables. Perception \& Psychophysics, 30, 411-416.
Elliott, L. L., Longinotti, C., Meyer, D., Raz, I., \& Zucker, K. (1981). Developmental differences in identifying and discriminating CV syllables. Journal of the Acoustical Society of America, 70, 669-677.

HAYES, D. (1981). Central auditory problems and the aging process. In D. S. Beasley \& G. A. Davis (Eds.), Aging, communication processes and disorders. New York: Grune \& Stratton.

KLATT, D. H. (1980). Software for a cascade/parallel formant synthesizer. Journal of the Acoustical Society of America, 67, 971-995.

KonIG, E. (1957). Pitch discrimination and age. Acta Otolaryngologica, 48, 475-489.

LeviTt, H. (1971). Transformed up-down methods in psychoacoustics. Journal of the Acoustical Society of America, 49, 467-477.

Patterson, R. D., Nimmo-Smith, I., Weber, D. L., \& Milroy, R. (1982). The deterioration of hearing with age: Frequency selectivity, the critical ratio, the audiogram, and speech threshold. Joumal of the Acoustical Society of America, 72, 1788-1803.

SAlthouse, T. A. (1982). Adult cognition: An experimental psychology of human aging. New York: Springer-Verlag.

TURNER, C. W., Nelson, D. A. (1982). Frequency discrimination in regions of normal and impaired sensitivity. Journal of Speech and Hearing Research, 25, 34-41.

WECHSLER, D. (1981). Wechsler Adult Intelligence Scale-Revised. New York: Psychological Corp.

Wier, C. C., Jesteadt, W., \& Green, D. M. (1977). Frequency discrimination as a function of frequency and sensation level. Journal of the Acoustical Society of America, 61, 178-184.

Woodcock, R. W., \& Johnson, M. B. (1978). Psychoeducational battery. Hingham: Teaching Resources.

\section{NOTE}

1. The level of $90 \mathrm{~dB}$ SPL was selected to be certain the critical information of the initial consonants would be audible to all listeners.

(Manuscript received August 30, 1984;

revision accepted for publication February 28, 1985.) 